\title{
Estimating the support effect of energy-absorbing rock bolts based on the mechanical work transfer ability
}

Xuezhen $\mathrm{Wu}^{1,2}$, Yujing Jiang ${ }^{2,3}$, Zhenchang Guan ${ }^{1}$, Gang Wang ${ }^{3}$

${ }^{1}$ College of Civil Engineering, Fuzhou University, Fuzhou 350108, China;

${ }^{2}$ Graduate School of Engineering, Nagasaki University, Nagasaki 852-8521, Japan;

${ }^{3}$ State Key Laboratory of Mining Disaster Prevention and Control Co-founded by Shandong Province and the Ministry of Science and Technology, Shandong University of Science and Technology, Qingdao 266590, China;

Corresponding author: Yujing Jiang

Email: jiang@nagasaki-u.ac.jp

Corresponding Address: Bunkyo Machi 1-14, Nagasaki 852-8521, Japan.

Phone: +81-080-3118-5202 Fax: +0532-86057957 
Abstract: Energy-absorbing rock bolts have been widely used for rock reinforcement in mining and civil engineering under high-stress conditions. However, the mechanism of the interaction between the energy-absorbing rock bolt and rock mass is still not entirely clear at present; no analytical model is available for the qualitative prediction of its reinforcement effect. In this work, first, the deformation mechanism of the mainstream energy-absorbing rock bolt has been reviewed. An interaction model is proposed to describe the interaction between the energy-absorbing rock bolt and the rock mass. Based on the plane-strain axial symmetry assumption and the incremental theory of plasticity, the equilibrium equations and compatibility equations of rock mass, as well as the response of the energy-absorbing rock bolt are deduced theoretically. The proposed method was programmed in a Visual Basic environment, and a semi-analytical solution for the coupling model was achieved. The reinforcement mechanism of the energy-absorbing rock bolt in conventional tunneling is clearly demonstrated through an illustrative case study. The reinforcement effect of the energy-absorbing rock bolt under different conditions was estimated quantitatively, and its mechanical work transfer ability is presented. In addition, the validity of the proposed method was verified through numerical simulations. Finally, a number of derivative cases were investigated to reveal the influence of the bolt and rock properties on the reinforcement effect and the bolt work transferred on the rock mass. In the case of higher in-situ stress or low-strength rock mass, the support effect of the energy-absorbing rock bolt is significantly improved, and the bolt absorbs more energy. Increasing the bolt installation density could always be helpful for the stabilization of the surrounding rock mass. However, additional rock-bolt length could hardly affect ground reinforcement because the bolt section embedded in the elastic region of the rock mass could barely help to constrain the elastic displacement release. The bolt should be installed no later than the stage of critical inner pressure, namely when the plastic region occurs. The results also confirmed that the bolt work transferred on the rock mass is a satisfactory estimation index, which is helpful for the support system design.

Keywords: energy-absorbing rock bolt; interaction model; semi-analytical solution; mechanical work; support system design; ground responses. 


\section{Introduction}

High stress in surrounding rock mass can cause severe stability problems, such as massive squeezing and rock burst [1-4]. It has been observed that numerous conventional rock bolts failed when experiencing large displacement of rock mass $[5,6]$. This phenomenon implies that they are too stiff to sustain large deformation and dynamic conditions [7, 8]. The energy-absorbing bolt, which is also called the yielding rock bolt, has been widely used for rock reinforcement in mining and civil engineering under the aforementioned conditions [9].

According to Windsor [10], the types of rock bolts can be classified as: (1) continuously mechanically coupled (CMC), (2) continuously frictionally coupled (CFC), and (3) discretely mechanically or frictionally coupled (DMFC). Several analytical models have been proposed, such as those presented by Li and Stillborg [11], Cai et al. [12, 13], Guan et al. [14], Carranza-Torres. [15], Tan C. [16], and Farmer [17]. Most of them focused on the $\mathrm{CMC}$ and $\mathrm{CFC}$ rock bolts; however, the majority of the existing energy-absorbing rock bolts are of the DMFC bolt type [18-22].

For the DMFC bolt, solutions are only obtained by treating the contribution of the rock bolt as two uniformly compressive distributed loads applied at both ends of the bolts [15]. However, the assumption of the smeared contribution of the rock bolt is acceptable only under the premise of small bolt spacing [19]. The errors increase as the rock-bolt spacing increases. On the other hand, the sudden jump in radial stress of rock mass that appears at the distal end of the bolt will probably not occur in practice. Therefore, no analytical model is available for the qualitative prediction of the reinforcement effect of energy-absorbing rock bolt.

The mechanism of the interaction between the energy-absorbing rock bolt and the rock mass is substantially complex because of the yielding deformation of the rock bolt [19]. The supporting design that employs the energy-absorbing rock bolt is still empirical or semi-empirical, and it is difficult to evaluate its performance quantitatively. The mechanical work that the energy-absorbing rock bolt can transfer on the rock mass is an important ability, which can be used to estimate its support effect. Some researchers studied the energy absorbing ability of rock bolt by laboratory testing under dynamic loading condition, and the energy absorbing ability was evaluated by the energy released by impact hammer [18, 23]. However, there is no published research work that is focused on the energy transfer of rock bolt and rockmass during their interaction process by theoretical methods. Therefore, it is imperative to develop a reasonable model to predict the mechanical work transfer ability of energy-absorbing rock bolts in practical engineering and to 
quantify their performance in the context of the supporting design.

This study is focused on estimating the quasi-static reinforcement effect of energy-absorbing rock bolts according to their mechanical work transfer ability using an analytical method. After a brief review of the mainstream energy-absorbing rock bolts, a coupling model will be proposed to describe the interaction between the energy-absorbing rock bolt and the rock mass, as well as the influence of the bolt and rock properties on the reinforcement effect; the mechanical work transfer ability will be highlighted through parameter studies.

\section{A brief review of energy-absorbing rock bolts}

Yielding support was first proposed and used in deep gold mines in South Africa by Cook and Ortlepp. The support system used in deep mines should be able to carry high loads and, in addition, accommodate large deformations of rock mass without experiencing serious damage in itself. Windsor and Thompson [10] were the first to propose the concept of the ideal rock bolt, which should have the strength of a rebar and the deformation capacity of a Split Set bolt, along with the ability to be rapidly mobilized to a load level similar to the strength of the bolt material.

Extensive research and development work on yielding rock support has been conducted in recent years. Certain energy-absorbing rock bolts have been successfully developed and applied in coal mines and gold mines. According to the yielding mechanism, they can be classified into two types: the type with sliding structural components and the steel-deformation type.

The type with sliding structural components mainly includes the Cone bolt [20], the Roofex, the cold drawing bolt [21], and the He bolt [22]. The Cone bolt consists of a smooth steel bar with a flattened conical flaring, which is designed to plough through the grout when the pull load exceeds a predefined value. The Roofex, the cold drawing bolt, and the He bolt are all based on steel-steel interactions with energy absorbing elements.

The typical representatives of steel-deformation energy-absorbing rock bolts are the bolts proposed by Ansell [23] and the D bolt [18]. Their typical characteristic is the existence of a smooth segment in the bolt, which can elongate by $14-22 \%$ at high-load levels. The anchors are fixed in the borehole with either cement grout or resin, while the smooth sections of the bolt between the anchors can deform freely in response to rock dilation.

\section{Reinforcement mechanism of the energy-absorbing rock bolt}

\subsection{Generalized model of the energy-absorbing rock bolt}


Regardless of their different types, most energy-absorbing rock bolts can be represented through a generalized model. As shown in Fig. 1, the interaction mechanism between the energy-absorbing rock bolt and the rock mass is concisely illustrated. The total length of the bolt can be divided into three segments: the outer anchoring segment, the free-elongating segment, and the inner anchoring segment [24-26].

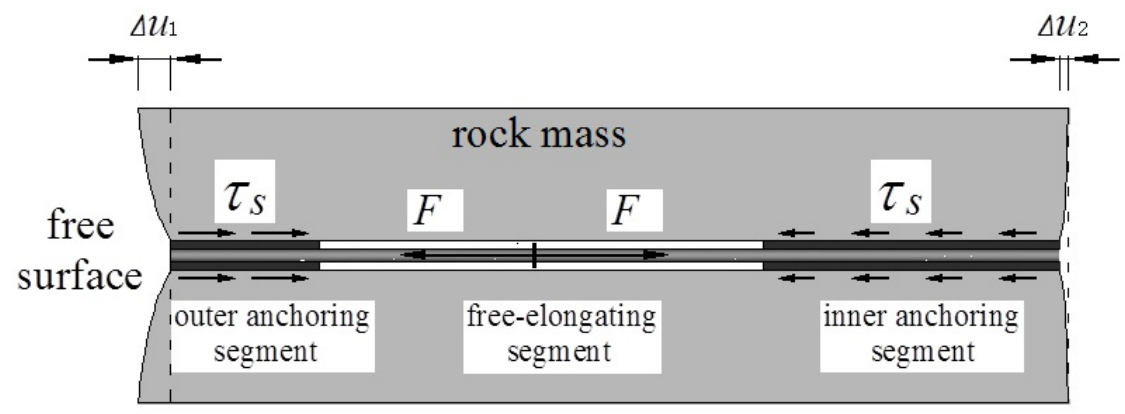

Fig. 1. The interaction mechanism between the energy-absorbing rock bolt and the rock mass.

After excavation, the surrounding rock mass will deform toward the excavation space. The outer anchoring segment of the energy-absorbing rock bolt will exert a stress on the rock mass to prevent its outward movement and transfer a positive work. In contrast, the stress of the inner anchoring segment points to the free surface, which results in a negative work.

With the increasing rock mass displacement, the axial force of the rock bolt will increase at an early stage. Once the pre-set sliding load is reached, the free-elongating segment starts to function and the bolt load will remain constant, thus preventing the self-destruction of the energy-absorbing rock bolt, whereas the work transferred by the rock bolt will increase continuously.

\subsection{The conventional spring-slider model}

According to the pullout tests for passive bolts, the failure of the fully grouted bolts typically occurs at the bolt-grout interface, the grout-rock interface, the grout itself, and the rock matrix [27]. These four failure modes are generalized into conventional spring-slider model. The conventional spring-slider model can simulate the properties of CMC and CFC bolts, however, it not very suitable for energy-absorbing rock bolts, which are of the DMFC bolt type. On the other hand, there is no slider element in the bolt itself in the conventional model; therefore, the large deformation properties of energy-absorbing rock bolts cannot be expressed.

\subsection{Interaction model of energy-absorbing rock bolt and rock mass}

The energy-absorbing rock bolt is characterized by its large deformation properties, which means that the bolt can elongate to limit the axial load, and transfer more work on the rock mass. According to the 
characteristics of the energy-absorbing rock bolt, an interaction model is proposed, as shown in Fig. 2(a). The spring between the bolt and the anchor hole, which controls the interaction between the rock mass and the rock bolt, represents the shear stiffness of the anchoring agent. Its characteristic curve is shown in Fig. 2 (b). Endpoint A signifies that the relative displacement and the shear stress between the rock mass and the rock bolt will cease to increase, as the free-elongating segment starts to elongate. The slider and spring at the middle of the model represent the free-elongating segment, and the deformation characteristic curve is shown in Fig. 2 (c), where $d F / d r$ is the shear force per unit length, and $F$ is the axial force of bolt; $u_{s}$ is the relative shear displacement of the bolt and rock mass; $u_{b}$ is the relative displacement of the outer anchoring segment and the inner anchoring segment. The elongation characteristic of the energy-absorbing rock bolt is controlled by the slider. The elastic elongation characteristic of the bolt itself, namely the axial stiffness of the bolt material, is controlled by the spring at the axial direction. In this model, the function of the bolt plate is replaced by the shear stress between the rock bolt and the rock mass at the outer end of the rock bolt; therefore, the shear failure of grout in the outer anchoring segment will not be considered. The bonding properties of inner and outer anchoring segment can be determined by pull tests. The free segment of the energy-absorbing rock bolt will start to elongate when the shear stress at the inner anchoring segment is excessively large, thus preventing shear failure between the rock bolt and the rock mass in this segment. Therefore, the slider unit between the rock bolt and the rock mass in the classic spring-slider model has been removed in the new model.

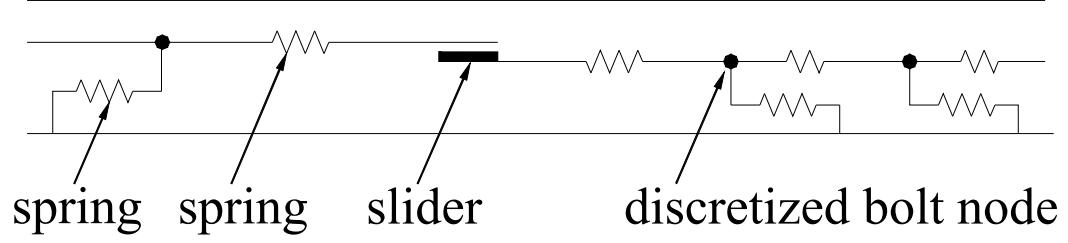

(a)

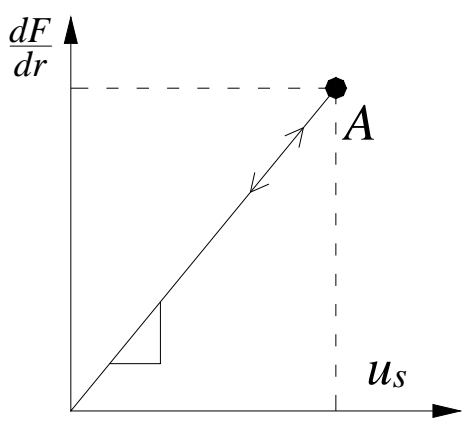

(b)

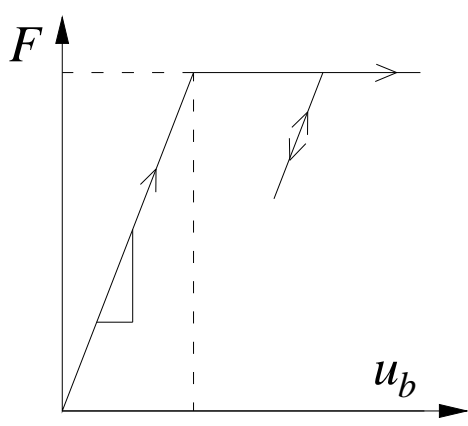

(c)

Fig. 2. The coupling model of energy-absorbing rock bolt and rock mass: (a) the overall structure model of 
energy-absorbing rock bolt; (b) the shear force per unit length versus relative shear displacement in anchoring segments; (c) the axial force versus displacement in free segment.

The shear stress between the rock bolt and the rock mass per unit length is controlled by a shear spring that is characterized by the shear stiffness of the anchoring agent, $K_{s}$, and the relative shear displacement, $u_{s}$. The relative shear displacement is a variable which is different at all the points along the rock bolt. The relationship between shear force per unit length, $d F / d r$, and the relative shear displacement, $u_{s}$, is illustrated in Fig. 2(b). The shear force per unit length is proportionally mobilized by the relative shear displacement, as expressed in Eq. (1):

$$
d F / d r=K_{s} u_{s}
$$

Dividing the shear force per unit length by the bolt perimeter $\pi D_{s}$, the shear stress around the bolt, $\tau_{s}$, can be formulated as Eq. (2). Where, $D_{s}$ is the diameter of rock bolt, $K_{s}$ is shear stiffness of the anchoring agent.

$$
\tau_{s}=\frac{d F}{\pi D_{s} d r}=\frac{K_{s} u_{s}}{\pi D_{s}} \quad\left(\tau_{s} \leq \tau_{s}^{s e t}\right)
$$

Integrating the shear force per unit length along the bolt axis, the axial force of the bolt can be obtained via Eq. (3).

$$
F=\int K_{s} u_{s} d r \quad\left(F \leq F^{\mathrm{set}}\right)
$$

Here, $F^{\text {set }}$ is the pre-set sliding load of the energy-absorbing rock bolt, and $\tau_{s}^{\text {set }}$ is the corresponding maximum shear stress around the bolt.

According to the balance equation of the bolt itself, the axial forces caused by the inner and outer anchoring sections are equal, and are lower than the maximum pre-set load capacity of energy-absorbing rock bolt. Assuming that $\mathrm{a}$ and $\mathrm{b}$ are the outer and inner boundaries of the free section, and that the stiffness of the outer anchor and inner anchor are $K_{s 1}$ and $K_{\mathrm{s} 2}$, respectively, we can then obtain the following equation, where $L_{b}$ is the total length of rock bolt.

$$
\int_{0}^{a} K_{s 1} u_{s} d r=-\int_{b}^{L_{b}} K_{s 2} u_{s} d r
$$

With the unloading of the in-situ stress from initial stress to the final one after a tunnel excavation, the displacement of the surrounding rock mass increases gradually, and the shear force of the rock bolt continuously transfers work on the rock mass. The work done by the shear force at a length of $d r$, after an instant relative shear displacement $d u_{\mathrm{s}}$ at a certain stage can be formulated as: 


$$
d^{2} W=d F d u_{s}=K_{s} u_{s} d r d u_{s} .
$$

Integrating $d^{2} W$ along the bolt axis, the work of the rock bolt at this stage can be obtained via Eq. (6).

$$
d W=\int d F d u_{s}=\int K_{s} u_{s} d u_{s} d r .
$$

Integrating $d W$ along the unloading pass of the in-situ stress from $P_{0}$ to the final pressure, the total work of the rock bolt can be obtained via Eq. (7).

$$
W=\iint K_{s} u_{s} d r d u_{s} .
$$

The most important properties involved in this model, the $K_{s}$, can be evaluated from the conventional pullout tests [28]. The rest of the properties of the rock bolt can be obtained directly from the specifications of the manufacturer.

\section{Equilibrium equations for anchored rock mass around a circular tunnel}

\subsection{Strain-softening behavior of rock mass}

In this study, the rock mass is assumed to satisfy the Mohr-Coulomb failure criterion and exhibit strain-softening behavior. The dilation factors in the strain-softening region and the plastic-flow region are considered identical, for the sake of simplicity. The major principal plastic strain, $\varepsilon_{1}{ }^{p}$, is employed as the softening parameter. Therefore, the failure criterion, $f$, and the plastic potential, $g$, can be formulated as follows:

$$
\begin{gathered}
f=\sigma_{1}-K_{p} \sigma_{3}-\sigma_{c}=0, \\
g=\sigma_{1}-K_{\psi} \sigma_{3}=0,
\end{gathered}
$$

with

$$
\sigma_{c}=\left\{\begin{array}{lr}
\sigma_{c}^{1}-\frac{\left(\sigma_{c}^{1}-\sigma_{c}^{2}\right) \varepsilon_{1}^{p}}{\alpha} & \left(0 \leq \varepsilon_{1}{ }^{p} \leq \alpha\right) \\
\sigma_{c}^{2} & \left(\varepsilon_{1}{ }^{p} \geq \alpha\right)
\end{array}, K_{p}=\frac{1+\sin \phi}{1-\sin \phi}, \quad K_{\psi}=\frac{1+\sin \psi}{1-\sin \psi} .\right.
$$

Here, $\sigma_{1}$ and $\sigma_{3}$ are the major and minor principal stresses of the rock mass, respectively; $\varepsilon_{1}^{p}$ is the major principal plastic strain, and serves as the softening parameter; $K_{p}$ and $K \psi$ are the passive coefficient and the dilation factor of the rock mass, respectively, which are regarded as constants within the complete plastic region; $\sigma_{c}$ is the compression strength, and transits gradually from $\sigma_{c}{ }^{1}$ to $\sigma_{c}{ }^{2}$, according to the evolution of the major principal plastic strain, $\varepsilon_{1}^{p} ; \alpha$ is a shift point of the softening parameter that distinguishes the strain-softening region from the residual region. 
The excavation of a long deep tunnel with a circular cross section under hydrostatic in-situ stress conditions can be considered as an axial-symmetry plane-strain problem, while neglecting the influence of gravity and restricting the out-of-plane principal stress as an intermediate stress. After a tunnel excavation, the surrounding rock mass will experience elastic, softening, and residual regions sequentially, according to different fictitious inner pressure exerted by the tunnel face and the support [29].

\subsection{Equilibrium equations for anchored rock mass}

The solution is based on the following assumptions: (1) the tunnel is deep; (2) the cross section is circular; (3) the problem is axisymmetric; (4) the ground is homogeneous and isotropic. The anchored zone contains the rock mass corresponding to the outer anchoring segment and the inner anchoring segment of the energy-absorbing rock bolt. The free zone includes the rock mass of the free-elongating segment and the rock mass without the bolt. The equilibrium equations for the rock mass in the anchored zone and the free zone will be established separately, as shown in Fig. 3.

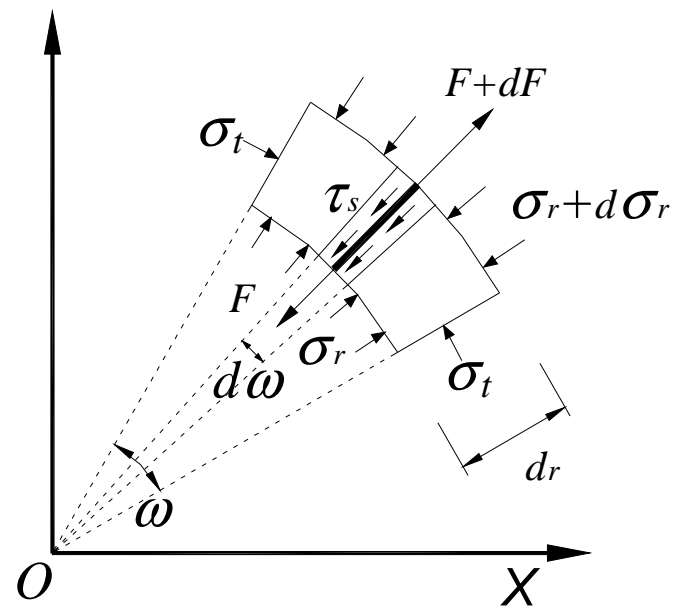

(a)

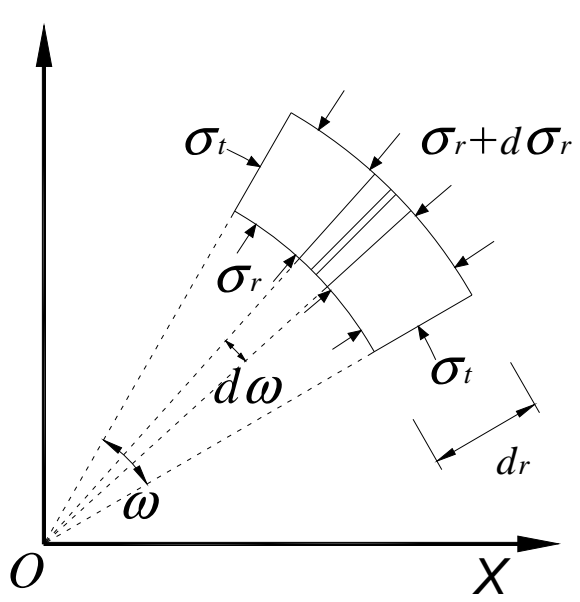

(b)

Fig. 3. The equilibrium condition for the anchored matrix mass: (a) the anchored-segment; (b) the free-segment.

For the anchored zone, consider an infinitesimal volume in the radial direction, as illustrated in Fig. 3(a). The rock mass is subjected to radial stress $\sigma_{r}$, tangential stress $\sigma_{t}$, and shear stress $\tau_{s}$ caused by the energy-absorbing rock bolt. The increment of the bolt axial force caused by shear stress is defined as $d F$, and the axial force is defined as F. According to the research of Li et al. [11], Cai et al. [12, 13], and Guan et al. [14] on conventional bolts, the axial force, $F$, can be distributed evenly, around its tributary area. The static equilibrium condition of the infinitesimal rock-mass volume can be formulated as:

$$
\left(\sigma_{r}-\frac{F}{r \omega L_{z}}\right) r d \omega L_{z}+2 \sigma_{t} d r L_{z} \sin \frac{d \omega}{2}=\left(\sigma_{r}+d \sigma_{r}-\frac{F+d F}{(r+d r) \omega L_{z}}\right)(r+d r) d \omega L_{z} .
$$


Where, $L_{z}$ is the spacing of different rock bolts along the axial direction of tunnel. Meanwhile, considering the interaction at the bolt-rock interface, $d F$ can be expressed as:

$$
d F=\tau_{s} \pi D_{s} d r
$$

Associating Eq. (10) with Eq. (11), noticing that $\sin \left(\frac{d \omega}{2}\right)$ approximately equals to $\frac{d \omega}{2}$ because $d \omega$ is infinitesimal, the equilibrium equation can be deduced:

$$
\frac{d \sigma_{r}}{d r}=\frac{\sigma_{t}-\sigma_{r}+N_{0} \tau_{s}}{r} \text { with } N_{0}=\frac{\pi D_{s}}{\omega L_{z}}
$$

In the present work, the constant $N_{0}$ is referred to as the geometry coefficient because it is entirely determined by the geometrical properties of the bolts.

For the free zone shown in Fig. 3(b), the shear stress between the bolt and the rock mass is zero. The equilibrium equation can be formulated as:

$$
\frac{d \sigma_{r}}{d r}=\frac{\sigma_{t}-\sigma_{r}}{r}
$$

The above equation can be seen as equal to the equilibrium equation, Eq. (12), when $N_{0}$ is set to zero. Therefore, Eq. (12) can be regarded as a uniform equation, regardless of the different zones.

\subsection{Displacement compatibility equations for the rock mass}

Based on the plane-strain axial symmetry assumption, the relationships of strain and displacement for the rock mass can be simplified as:

$$
\frac{d u}{d r}=\varepsilon_{r} \frac{u}{r}=\varepsilon_{t},
$$

where $\varepsilon_{r}$ is the strain in the radial direction, and $\varepsilon_{t}$ is the strain in the tangential direction.

According to Hook's law, the tangential strain of the rock mass can be evaluated from its stress state in the elastic region, as formulated as in Eq. (15).

$$
\varepsilon_{t}=\left(\frac{\sigma_{t}}{E}-v \frac{\sigma_{r}}{E}-v \frac{2 P_{0} v}{E}\right)-\left(\frac{P_{0}}{E}-v \frac{P_{0}}{E}-v \frac{2 P_{0} v}{E}\right)
$$

Here, $E$ and $v$ are the Young's modulus and the Poisson's ratio of the rock mass, respectively. $P_{0}$ is the in-situ rock stress. It should be noted that only the strain caused by the tunnel excavation is considered, which means the initial strain owing to the in-situ stresses has been removed. Then, associating Eq. (14) with Eq. (15) and considering the hydrostatic in-situ stress condition, the displacement compatibility equation for the elastic region can be formulated as in Eq. (16). 


$$
u=r \varepsilon_{t}=\frac{P_{0}-\sigma_{r}}{E}(1+v) r
$$

For the plastic region, the loading path in this problem refers to a monotonic decrease in the fictitious inner pressure, corresponding to the advancing of the tunnel face. Consequently, the rates of all mechanical variables can be evaluated through their first-order derivatives with respect to $P_{i}$. The incremental theory of plasticity assumes that the total strain rate consists of both an elastic part and a plastic part, as shown in Eq. (17) [30]. The elastic part is controlled by Hooke's law and the plastic part by the potential flow rule, as formulated in Eq. (18) and Eq. (19), respectively. The relationship between the strain rate and the displacement velocity is simplified by virtue of axial symmetry, and is described by Eq. (20):

$$
\begin{gathered}
\dot{\varepsilon}_{r}=\dot{\varepsilon}_{r}{ }^{e}+\dot{\varepsilon}_{r}{ }^{p}, \quad \dot{\varepsilon}_{\theta}=\dot{\varepsilon}_{\theta}{ }^{e}+\dot{\varepsilon}_{\theta}{ }^{p} ; \\
\dot{\varepsilon}_{r}{ }^{e}=\frac{1-v}{2 G} \dot{\sigma}_{r}-\frac{v}{2 G} \dot{\sigma}_{\theta}, \quad \dot{\varepsilon}_{\theta}{ }^{e}=\frac{1-v}{2 G} \dot{\sigma}_{\theta}-\frac{v}{2 G} \dot{\sigma}_{r} ; \\
\dot{\varepsilon}_{r}^{p}=\lambda \frac{\partial g}{\partial \sigma_{r}}=\lambda, \quad \dot{\varepsilon}_{\theta}{ }^{p}=\lambda \frac{\partial g}{\partial \sigma_{\theta}}=-\lambda K_{\psi} ; \\
\dot{\varepsilon}_{r}=\frac{\partial \dot{u}}{\partial r}, \quad \dot{\varepsilon}_{\theta}=\frac{\dot{u}}{r} .
\end{gathered}
$$

Here, $g$ is the plastic potential that has been defined in Eq. (9). The rates of all mechanical variables (denoted by a dot mark) are expressed via their first-order derivatives with respect to $P_{i}$. Then, associating Eqs. (17) through (20), and by eliminating the multiplier $\lambda$, the displacement compatibility equation for the plastic region can be expressed as:

$$
\frac{\partial \dot{u}}{\partial r}+K_{\psi} \frac{\dot{u}}{r}=\frac{\left(1-v-v K_{\psi}\right)}{2 G} \dot{\sigma}_{r}-\frac{\left(v K_{\psi}-K_{\psi}+v\right)}{2 G} \dot{\sigma}_{\theta}
$$

\section{Semi-analytical solutions for the equilibrium equations}

Estimation of the support system required to stabilize a tunnel opening is a four-dimensional problem, which not only concerns with three spatial dimensions but also the temporal dimension. The unexcavated rock mass in front of working face plays an important role in stabilizing the tunnel opening, which can be seen as an artificial inner pressure applied at the surface of surrounding rock mass. The artificial inner pressure, $P_{i}$, decreases from the in-situ stress, $P_{0}$, to the final pressure from the tunnel lining, thus corresponding to the advancing process of the tunnel face.

\subsection{Process of the solution}

The equilibrium equations, the displacement compatibility equations, and the bolt-rock interaction 
equations presented above can only be solved numerically. A two-dimensional finite difference algorithm (i.e., along the unloading path and along the radial direction) was employed. All variables describing the mechanical state of the surrounding rock mass have two indices: the first $(k)$ indicates a certain stage in the unloading path, and the second (i) indicates a certain position in the radial direction. Assuming that at a former stage (e.g., the $(k-1)^{\text {th }}$ stage, where $\left.P_{i}=P_{i}^{(k-1)}\right)$, all the mechanical states of the rock mass are known, the objective is to evaluate all the mechanical states at the current stage (i.e., the $k^{\text {th }}$ stage, where $P_{i}=P_{i}^{(k)}$ ) according to their known counterparts at the former stage; the evaluation process includes the following three steps along the length direction of the rock bolt: stress evaluation, displacement evaluation, and bolt responses evaluation. After the completion of one iteration, these known mechanical states at the current stage can be used for the evaluation of the mechanical states at the next stage (i.e., the $(k+1)^{\text {th }}$ stage, where $\left.P_{i}=P_{i}^{(k+1)}\right)$, by following the same three steps. This type of iteration is repeated until the final stage, where $P_{i}=P_{i_{-}}$final. The effect of the support time is illustrated through the value of the artificial inner pressure, $P_{i}$ install, when the energy-absorbing rock bolt is installed.

\subsection{Stress evaluation of the rock mass}

At the current stage, the radial stress at the tunnel wall, $\sigma_{r}\left(k, R_{a}\right)$, is known and equals to $P_{i}^{(k)}$, which serves as the boundary condition of the equilibrium equations. According to Eq. (12) and the failure criterion, the radial and tangential stresses can be obtained from the Runge-Kutta method. When the radial stress increases up to the critical inner pressure $P_{i}^{c r i}$, the position should be recorded as the radius of the elastoplastic interface $R_{e}$; then, the stress state of the elastic region should be evaluated. According to the research of Alonso [31], $\sigma_{r e}$ is a constant that only depends on the properties of the rock mass itself, and is independent of the position of the elastoplastic interface. The critical inner pressure can be calculated via the following formula.

$$
P_{i}^{c r i}=\sigma_{r e}=\frac{2 P_{0}-\sigma_{c}^{1}}{K_{p}+1}
$$

The bolt-rock shear stress and the transitional strength of the rock mass at the former stage are required during this step; the radial and tangential stresses at the current stage can be determined after the stress evaluation process.

\subsection{Displacement evaluation of the rock mass}

For the elastic region, the radial displacement of the rock mass at the current stage can be evaluated directly via the radial stress of the rock mass at the current stage, according to Eq. (16). For the plastic 
region, the fourth-order Runge-Kutta method is utilized again for the evaluation of the deformation rate at each consecutive calculation point (inward radial direction), according to the compatibility equations (21). Finally, the displacement at the current stage can be obtained by accumulating the displacement increment at the current stage to its counterpart at the former stage. After the displacement evaluation, the major principle plastic strain $\mathcal{E}_{t}^{p}$ at the current stage, which here serves as the softening parameter, can be obtained. Then the transitional strength, $\sigma_{c}(k, r)$, at the current stage can also be computed via Eq. (8).

The displacements $u(k-1, r)$ and the stresses $\sigma_{r}(k-1, r), \sigma_{t}(k-1, r)$ at the former stage, as well as the stresses at the current stage, are required in this step. The displacement, $u(k, r)$, and the transitional strength, $\sigma_{c}(k, r)$, at the current stage can be determined after the displacement evaluation process.

\subsection{Interaction between the energy-absorbing rock bolt and the rock mass}

Let us assume that the bolts are mounted at the $j^{\text {th }}$ stage, where $P_{i}=P_{i_{-}}$install. The displacement of the rock mass at every point, $u_{m o b}$, should be first computed.

The displacement of the rock mass is larger than that of the rock bolt at the surface of the tunnel, whereas the opposite occurs at the bottom end of the energy-absorbing rock bolt. Hence, a point must exist where the displacement of the rock mass is same as that of the rock bolt, and it is referred to as the nominal neutral point to distinguish it from the actual neutral point in the conventional rock bolt. Owing to the fact that the forces aroused from the outer anchoring segment and the inner anchoring segment are equal, the position of the nominal neutral point can be calculated via a numerical iterative method.

Assuming position $\rho$ for the nominal neutral point, the relative shear displacement, $u$, at the current stage can be computed via Eq. (23).

$$
\left.\begin{array}{l}
u(k, r)=u_{\text {mob }}(k, r)-u_{\text {mob }}(k, \rho)+u_{e}(k, r) \quad(r>\rho) \\
u(k, r)=u_{\text {mob }}(k, r)-u_{\text {то }}(k, \rho)-u_{e}(k, r) \quad(r<\rho)
\end{array}\right\},
$$

where $u_{\text {mob }}(k, \rho)$ denotes the mobilizing displacement at the neutral point, and $u_{e}(r)$ represents the elastic elongation of the bolt itself in relation to the nominal neutral point at different position. Then, using the assumed $u$, the bolt responses, $\tau_{s}(k, r)$ and $F_{n}(k, r)$, can be evaluated via Eq. (2) and Eq. (3). The total work of the rock bolt transferred on the rock mass can be evaluated via Eq. (7).

With the increase in the rock mass deformation, the bolt axial force will gradually increase. When the axial force reaches the pre-set sliding load, the free section of the energy-absorbing rock bolt starts to elongate, and the maximum axial force of the rock bolt will cease to change. In this case, the relative shear displacement between the rock bolt and the rock mass can be computed through Eq. (24). 


$$
\begin{aligned}
& \left.u(k, r)=u_{\text {mob }}(k, r)-u_{\text {mob }}(k, \rho)+u_{e}(k, r)+u_{\text {slide }}(k) \quad(r>\rho)\right\}, \\
& \left.u(k, r)=u_{\text {mob }}(k, r)-u_{\text {mob }}(k, \rho)-u_{e}(k, r)-u_{\text {slide }}(k) \quad(r<\rho)\right\} \text {, }
\end{aligned}
$$

where, $u_{\text {slide }}(k)$ represents the elongation of the bolt-free segment after yielding, and it can be obtained through numerical iterative calculation based on the fact that the maximum bolt axial force will not change.

The relative displacements at this stage and the bolt installation stage are required in this step. The proper bolt responses and the total work of the rock bolt transferred on the rock mass can be determined after the evaluation process of the bolt responses.

After these three steps, all the mechanical states at the current stage (including the stress and the displacement distribution of the rock mass, the shear stress, the axial force, and the work transferred of rock bolt) are known, and can be used at the next stage (i.e., the $(k+1)^{\text {th }}$ stage, where $\left.P_{i}=P_{i}^{(k+1)}\right)$.

\section{Application and verification through an illustrative case study}

The proposed method was programmed in a Visual Basic (VB) environment, and was verified through numerical simulations. In this section, an illustrative case study will be presented to demonstrate the reinforcement mechanics of the energy-absorbing rock bolt in tunneling.

\subsection{An illustrative case study}

We assumed that a circular tunnel with a design radius of $5 \mathrm{~m}$ is excavated under a hydrostatic in-situ stress of $10 \mathrm{MPa}$. The Young's modulus and Poisson's ratio of the rock mass is $1.0 \mathrm{e}^{9} \mathrm{~Pa}$ and 0.25 , respectively. The peak strength and residual strength of the rock mass is $5 \mathrm{MPa}$ and $3 \mathrm{MPa}$, respectively. The passive coefficient, $K_{p}$, and the dilation factor, $K_{\psi}$, of the rock mass is 3.0 and 1.33, respectively, and they are constant within the entire plastic region. The softening parameter, $\alpha$, is 0.0025 .

The total length of the bolt is $3 \mathrm{~m}$; the outer anchoring segment is $0.5 \mathrm{~m}$, the free-elongating segment is $1.8 \mathrm{~m}$, and the inner anchoring segment is $0.7 \mathrm{~m}$. The diameter of the rock bolt is $20 \mathrm{~mm}$, with a yielding strength of $300 \mathrm{kN}$. The Young's modulus of the rock bolt is $2.1 \mathrm{e}^{11} \mathrm{~Pa}$. The shear stiffness of the anchoring agent, $K_{s}$, is $35 \mathrm{MPa}$. The spacing between different rock bolts along the axial of tunnel is $1.0 \mathrm{~m}$, and the spacing along the circumferential of tunnel is $1.12 \mathrm{~m}$. The energy-absorbing rock bolt should be mounted at the stage when $P_{i}^{(j)}=P_{0} * 37.5 \%$, which is equal to the critical inner pressure for the rock mass in the present case.

The ground and bolt responses are shown in Figs. 4 to 7 (represented by solid lines). To highlight the reinforcement effect of the energy-absorbing rock bolt, the ground responses at the same stage - without bolt reinforcement—are also depicted in the aforementioned figures (represented by dashed lines). 


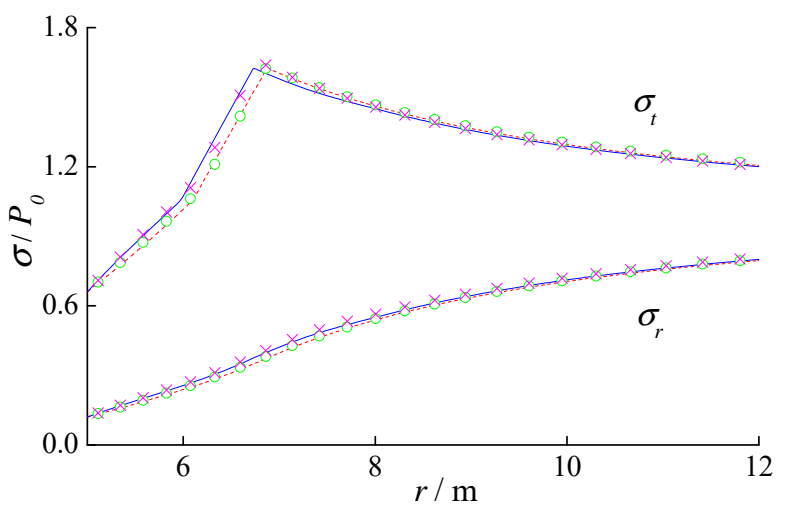

(a)

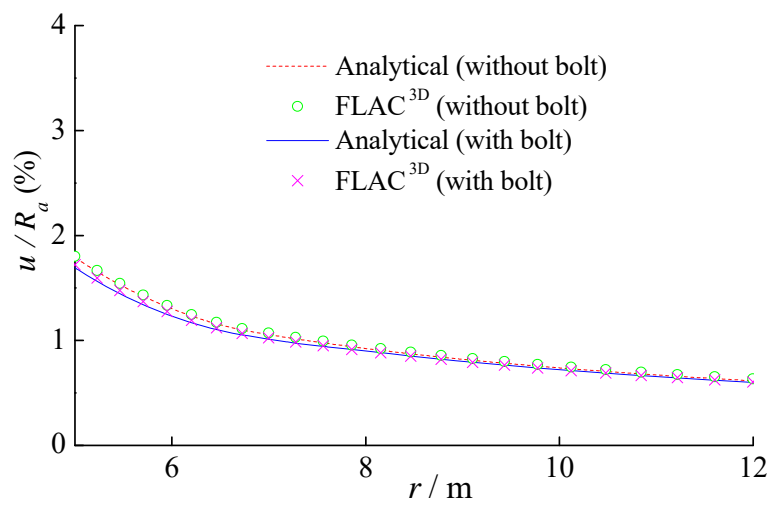

(b)

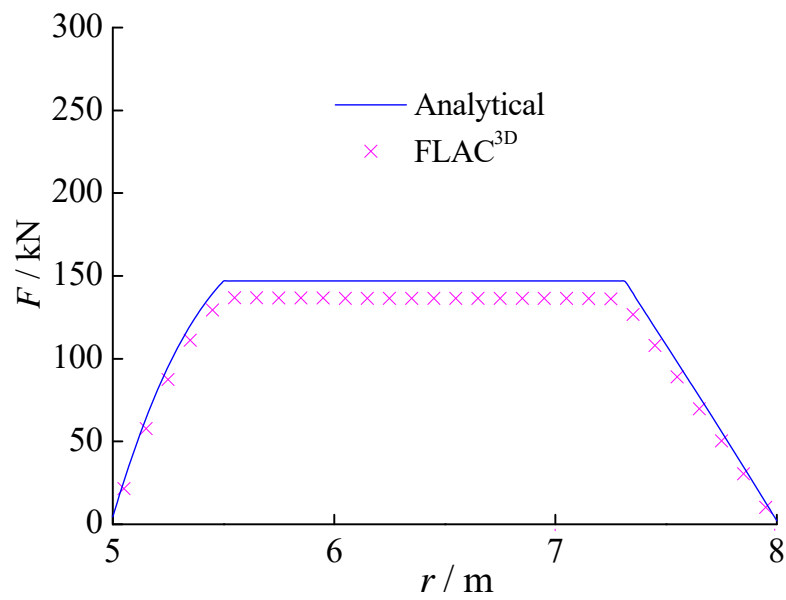

(c)

Fig. 4. The ground and bolt responses at $P_{i}=1.2 \mathrm{MPa}$ stage: (a) the stress distribution along the radial direction; (b) the displacement distribution along the radial direction; (c) the distribution of axial force along the bolt length. 


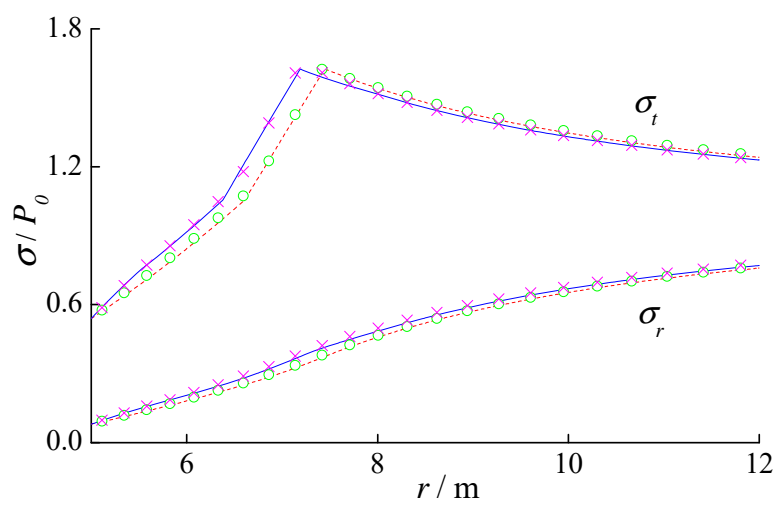

(a)

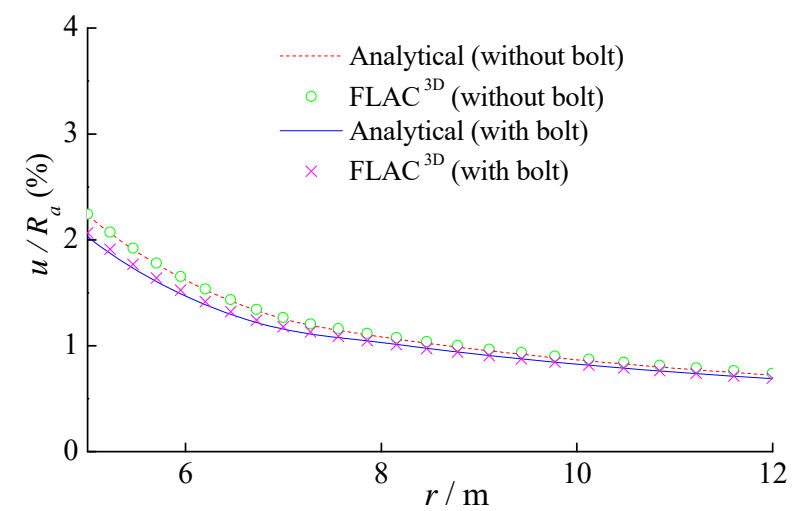

(b)

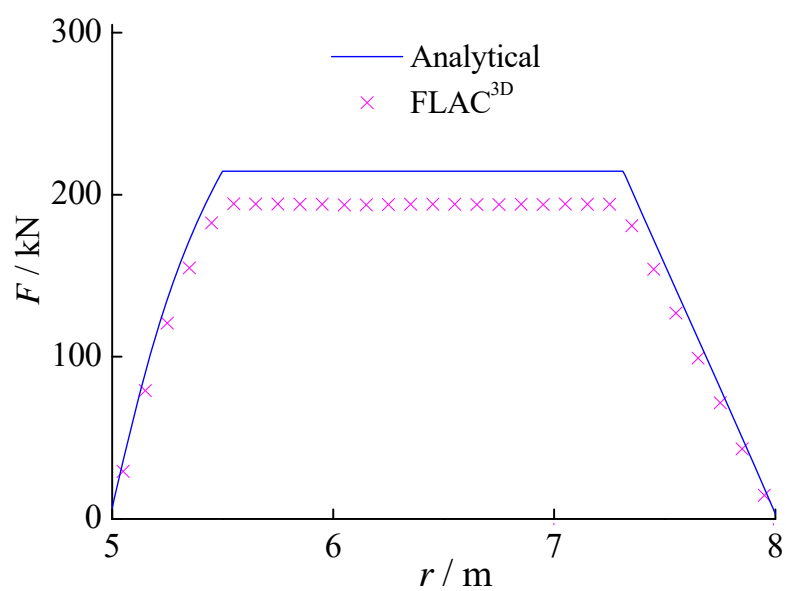

(c)

Fig. 5. The ground and bolt responses at $P_{i}=0.8 \mathrm{MPa}$ stage: (a) the stress distribution along the radial direction; (b) the displacement distribution along the radial direction; (c) the distribution of axial force along the bolt length. 


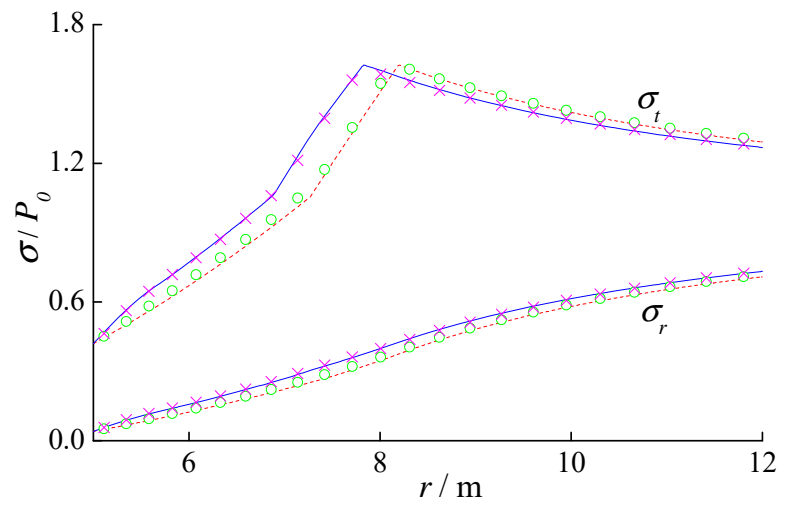

(a)

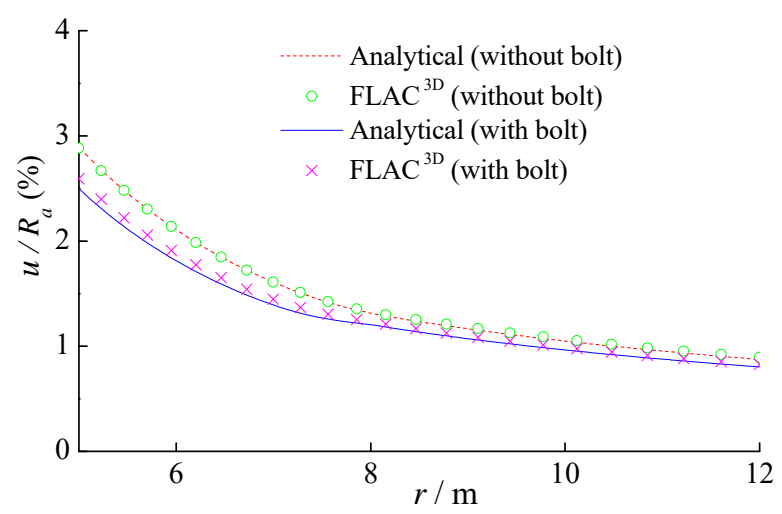

(b)

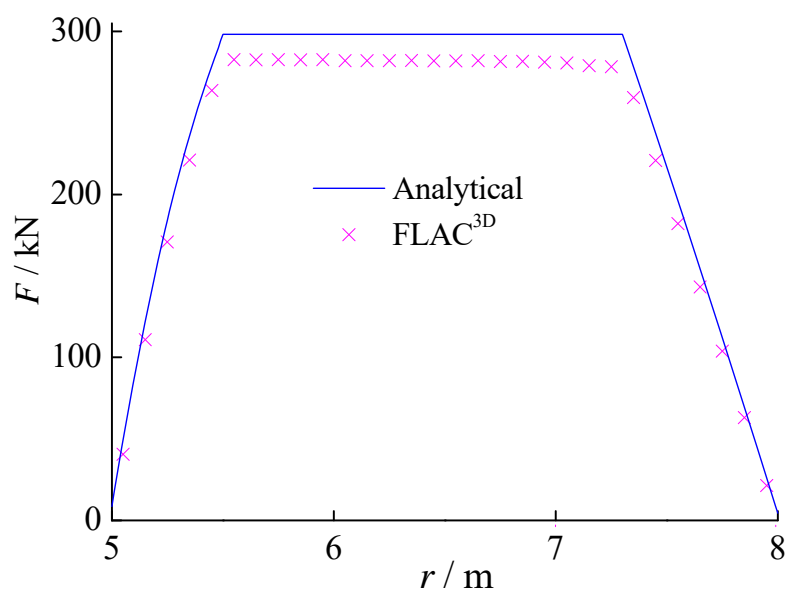

(c)

Fig. 6 . The ground and bolt responses at $P_{i}=0.4 \mathrm{MPa}$ stage: (a) the stress distribution along the radial direction; (b) the displacement distribution along the radial direction; (c) the distribution of axial force along the bolt length. 


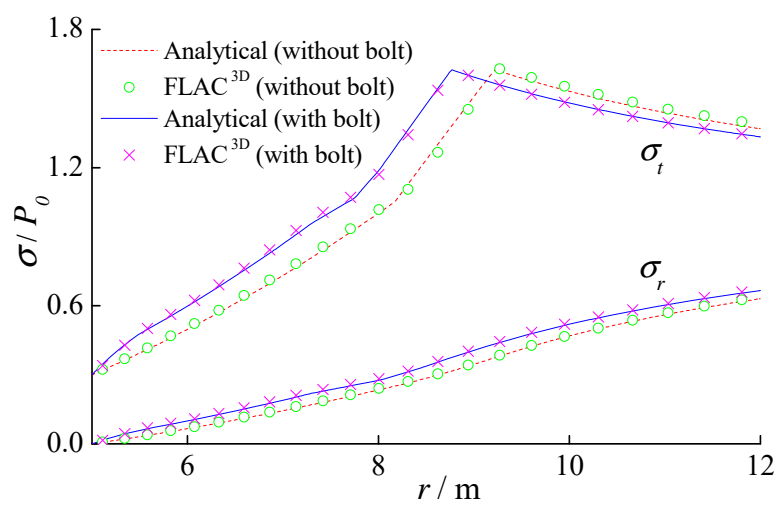

(a)

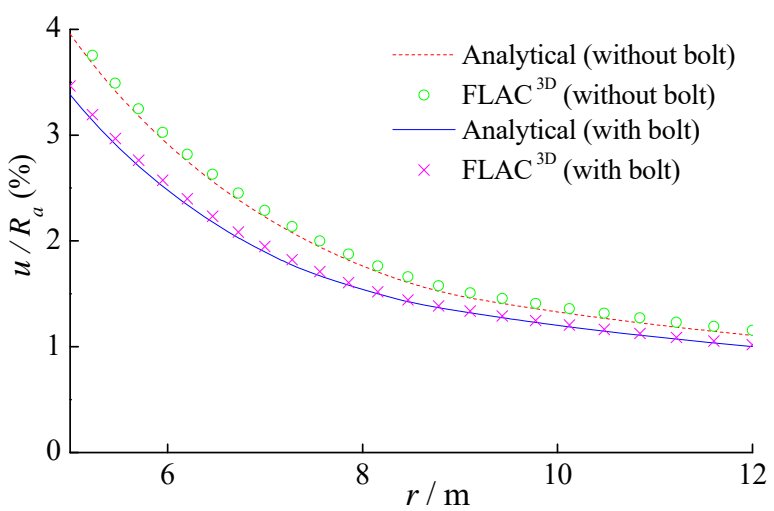

(b)

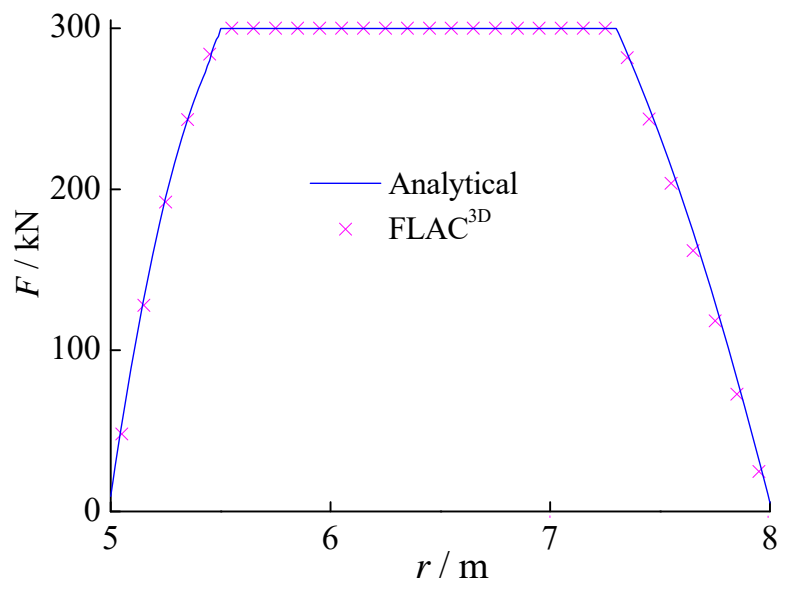

(c)

Fig. 7. The ground and bolt responses at $P_{i}=0.0 \mathrm{MPa}$ stage: (a) the stress distribution along the radial direction; (b) the displacement distribution along the radial direction; (c) the distribution of axial force along the bolt length.

With the decrease in the inner pressure for the rock mass, the displacement released by the rock mass increases, and the energy-absorbing rock bolts exert their effect gradually. At the $P_{i}{ }^{(k)}=1.2 \mathrm{MPa}$ stage as shown in Fig. 4, the reinforcement effect is not significant in relation to the displacement of the rock mass, 
and the maximum axial force along the energy-absorbing rock bolt is $145 \mathrm{kN}$. At the $P_{i}^{(k)}=0.8 \mathrm{MPa}$ stage as shown in Fig. 5, the maximum axial force is $215 \mathrm{kN}$, and the reinforcement effect increases gradually. At the $P_{i}^{(k)}=0.4 \mathrm{MPa}$ stage as shown in Fig. 6, the maximum axial force reaches $300 \mathrm{kN}$, indicating that the bolt is yielding and starts to elongate. At the $P_{i}^{(k)}=0.0 \mathrm{MPa}$ stage as shown in Fig. 7 (i.e., no lining is supported after the tunnel face has advanced ), the energy-absorbing rock bolts help constrain the convergence of the tunnel opening from $4.0 \%$ to $3.4 \%$. The analytical results show that the maximum axial force of the bolt is always $300 \mathrm{kN}$ after yielding, indicating that the large-deformation characteristic of the energy-absorbing rock bolt in this new model is well expressed.

The convergence confinement method is usually adopted in the support system design in conventional tunneling [31, 32]. Using the proposed method, the ground reaction curve (GRC) without bolt reinforcement, the bolted ground reaction curve (BGRC), and the bolt reaction curve (BRC) can be constructed by recording the displacement released at the tunnel wall, $u_{a}$, and the maximum axial force in the bolt, $F^{\max }$, at each unloading stage. The GRC, the BGRC, and the BRC in the illustrative case are depicted in Fig. 8.

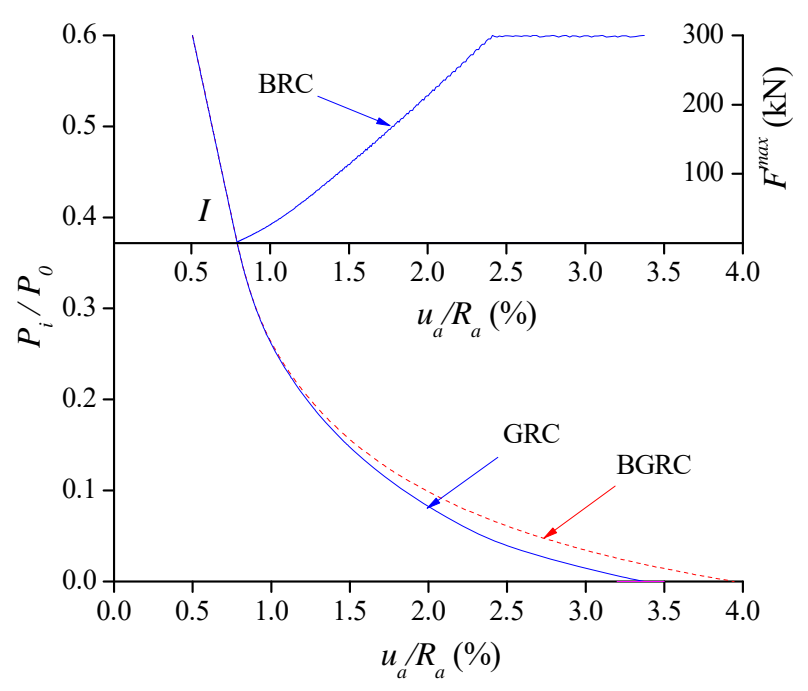

Fig. 8. The reinforced ground reaction curve and the bolt reaction curve. 


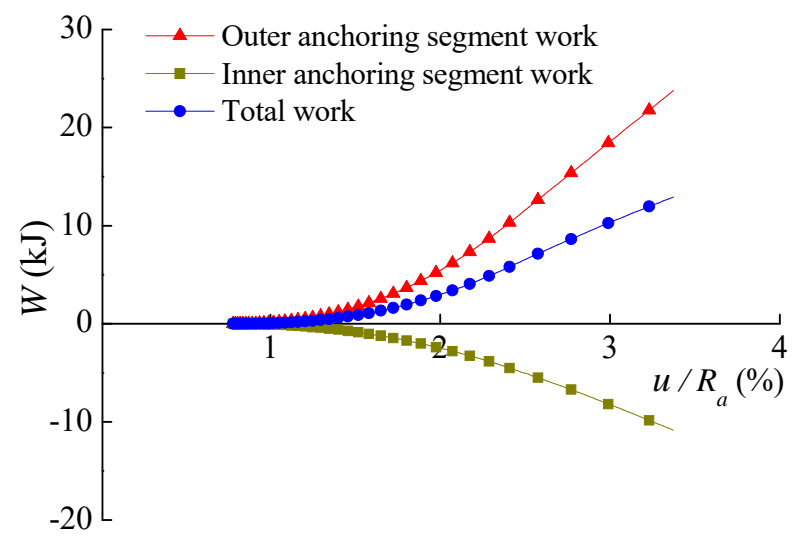

Fig. 9. The evolution of the total work transfer of the energy-absorbing rock bolt with the increase in the rock mass displacement.

The evolution of the total work of the energy-absorbing rock bolt with the increase in the rock mass displacement is shown in Fig. 9. The work transferred by the outer anchoring segment and inner anchoring segment are also depicted. As the outer anchoring segment applies a stress to prevent the rock-mass outward movement, it therefore transfers a positive work. The stress of the inner anchoring segment points toward the free surface, which will transfer a negative work. The total work of the energy-absorbing rock bolt is positive and gradually increases with the increase in rock-mass displacement.

\subsection{Verification through numerical simulations}

The validity of the proposed method was verified through numerical simulations (FLAC ${ }^{3 \mathrm{D}}$ software). The strain-softening constitutive laws in $\mathrm{FLAC}^{\mathrm{BD}}$ are characterized by six parameters: the bulk modulus $K$, the shear modulus $G$, the friction angle $\phi$, the cohesion $c$, the dilation angle $\psi$, and the softening parameter $\eta$. They were evaluated based on their counterparts that were employed in the analytical method. The parameters of rock bolt element used in FLAC model is the same with the analytical method.

The results from the numerical simulations are also depicted in Figs. 4 to 7, and are depicted as cross or dot marks. As shown in these figures, the ground and bolt responses computed through the proposed method and the numerical simulations are in excellent agreement, indicating that the semi-analytical solutions for the energy-absorbing rock bolt around the circular tunnel is valid. The proposed method can rationally elucidate the reinforcement mechanics of the energy-absorbing rock bolt in tunneling.

\section{Parameter analysis based on the new model}

Based on the proposed model, the influence of different parameters, including the stress condition, strength of rock mass, bolt space, bolt length, and the reinforcing time, on the reinforcement effect was quantitatively estimated. Considering the illustrative case as a standard case, and by varying every single 
parameter from $0 \%$ to $200 \%$ of its initial value, the relative significance of different parameters on the reinforcement effect can be illustrated.

In this study, the difference in the maximum tunnel convergence with and without the rock bolt $\Delta u_{\mathrm{x}}{ }^{\max }$, together with the maximum bolt axial force, $F_{\mathrm{x}}{ }^{\max }$, and the maximum bolt work, $W_{\mathrm{x}}{ }^{\max }$, were selected as the estimation indexes. The difference in the maximum tunnel convergence with and without the rock bolt highlights the reinforcement effect of the energy-absorbing rock bolt. The maximum bolt axial force and the maximum bolt work are the two self-indexes of the bolt working state. The indexes were divided by the values of $\left(\Delta u_{\mathrm{s}}^{\max }, F_{\mathrm{s}}{ }^{\max }, W_{\mathrm{s}}^{\max }\right)$ that were obtained in the illustrative case in order to obtain dimensionless values. The dimensionless values can better illustrate the sensitivity of the parameters and enable the comparisons among results that were obtained under different conditions.

\subsection{Influence of in-situ stress}

The in-situ stress of the rock mass was selected for the study of the influence of the application environment on the supporting effect of the rock bolt. The in-situ stress was varied from $0 \%$ to $200 \%$ of its initial value (10 MPa). Meanwhile, the other parameters were the same as those in the illustrative case. Fig. 10 presents the evolution of the tunnel convergence difference, the bolt axial force, and the bolt work as the in-situ stress increases. The results show that all three indexes are significantly low, when $P_{0}=5 \mathrm{MPa}$ $(50 \%)$. The maximum axial force is $72 \mathrm{kN}\left(0.24 * F_{\mathrm{s}}{ }^{\max }\right)$, whereas the tunnel convergence difference and the bolt work on the rock mass are both approximately equal to zero. With the increase in the in-situ stress, the tunnel convergence increases significantly; similar observation can be made for the bolt axial force and the bolt work. When the in-situ stress is greater than $10 \mathrm{MPa}$, the bolt axial force reaches the yielding strength of $300 \mathrm{kN}$ and remains constant, whereas the bolt work continuously increases, together with the tunnel convergence difference. In the case of higher in-situ stress, the support effect of the energy-absorbing rock bolt is considerably improved, and the bolt absorbs more energy. 


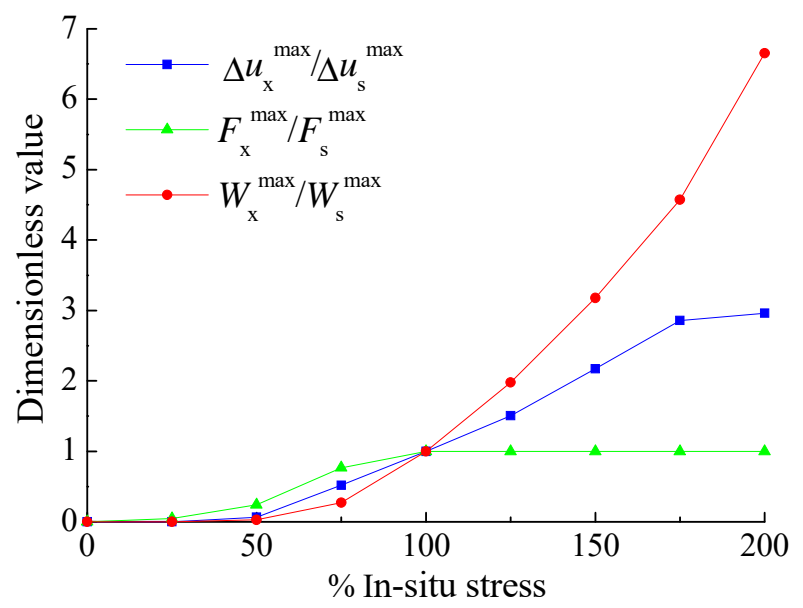

Fig. 10. The evolution of the tunnel convergence difference, the bolt axial force, and the bolt work as the in-situ stress increases.

\subsection{Influence of rock strength}

In the present section, the influence of rock strength will be studied. The peak strength and residual strength of the rock mass were varied from $25 \%$ to $200 \%$ of their initial value (5 $\mathrm{MPa}$ and $3 \mathrm{MPa}$, respectively), whereas the other parameters were the same as those in the illustrative case. Fig. 11 illustrates the evolution of the tunnel convergence difference, the bolt axial force, and the bolt work as rock strength increases.

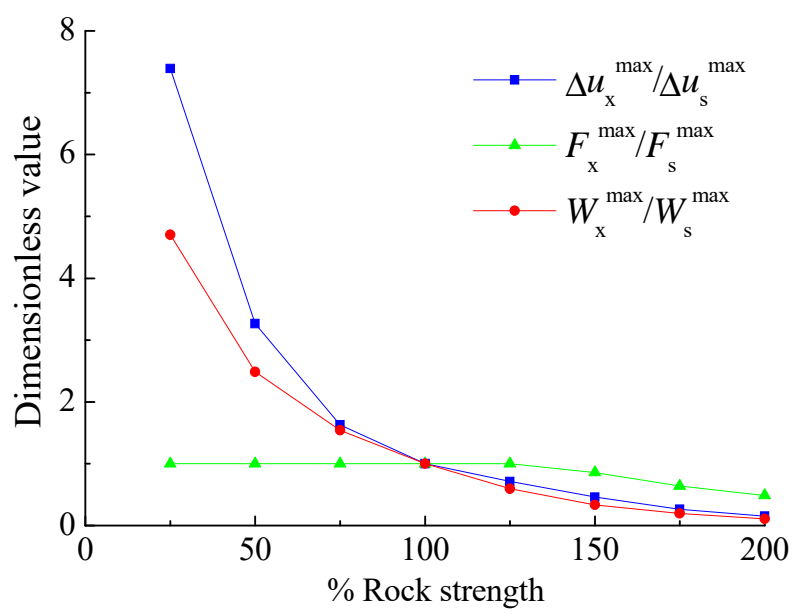

Fig. 11. The evolution of the tunnel convergence difference, the bolt axial force, and the bolt work as rock strength increases.

According to this figure, the influence of the rock strength on the supporting effect is similar to that of the rock stress. The typical characteristic is that the tunnel convergence difference, the maximum axial force, and the bolt work decrease with the increase in rock strength. In the case of lower rock strength, the support effect has significantly improved, and the bolt absorbs more energy.

In Figs. 10 and 11, it is obvious that the bolt work has a better correspondence with tunnel 
convergence difference than the bolt axial force. This phenomenon indicates that the bolt work transferred on the rock mass is a more effective estimation index of the supporting effect than the bolt maximum axial force. To further study this behavior, the evolution of the bolt axial force and the bolt work as the maximum tunnel convergence increases are shown in Fig. 12. The results show that the axial force of the energy-absorbing rock bolt increases rapidly and almost linearly with the increase in the maximum tunnel convergence before reaching the yielding strength of $300 \mathrm{kN}$. In the meanwhile, the bolt work transferred on the rock mass is quite small. When the maximum tunnel convergence exceeds $2 \%$ of the tunnel radius and the energy-absorbing rock bolt is in yielding state, the work starts to increase rapidly and linearly with the increase in tunnel convergence.

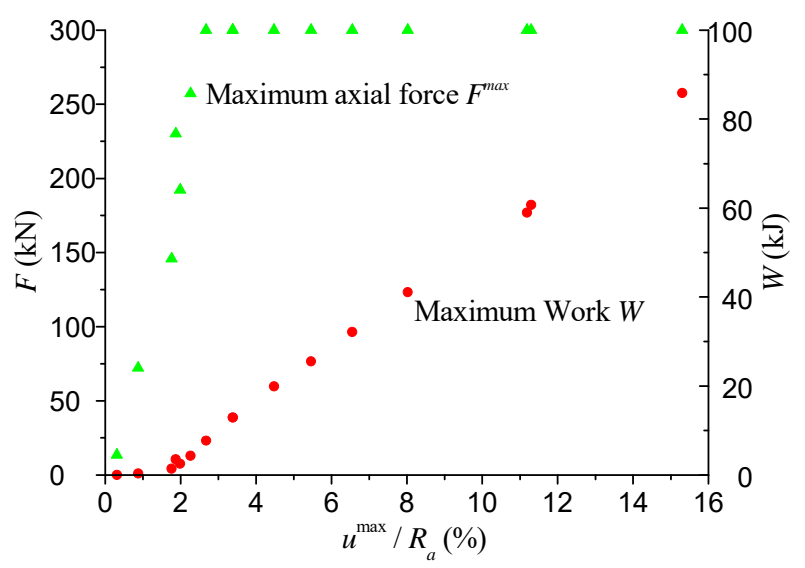

Fig. 12. The evolution of the bolt axial force and the bolt work as the maximum tunnel convergence increases.

The deformation characteristics of the energy-absorbing rock bolt play a highly important role in rock reinforcement. The performance of the energy-absorbing rock bolt is very satisfactory and absorbs a substantial amount of energy from the rock mass, even when the maximum tunnel convergence reached $16 \%$ of the tunnel radius. However, under this condition, the conventional rock bolt would be damaged, which indicates that the yielding support is necessary for a high-stress or low-strength rock mass. The satisfactory performance of the energy-absorbing rock bolt highlighted the advantages of the large-deformation supporting.

\subsection{Influence of the bolt space}

In this section, the influence of the bolt installation space, namely the bolt density, will be studied. The bolt space, including the longitudinal space and the circumferential space were varied from $50 \%$ to $200 \%$ of their initial value $(1 \mathrm{~m}$ and $1.12 \mathrm{~m})$, whereas the other parameters were the same as the ones of the illustrative case. Fig. 13 illustrates the evolution of the tunnel convergence difference, the bolt axial force, 
and the bolt work as the bolt space increases.

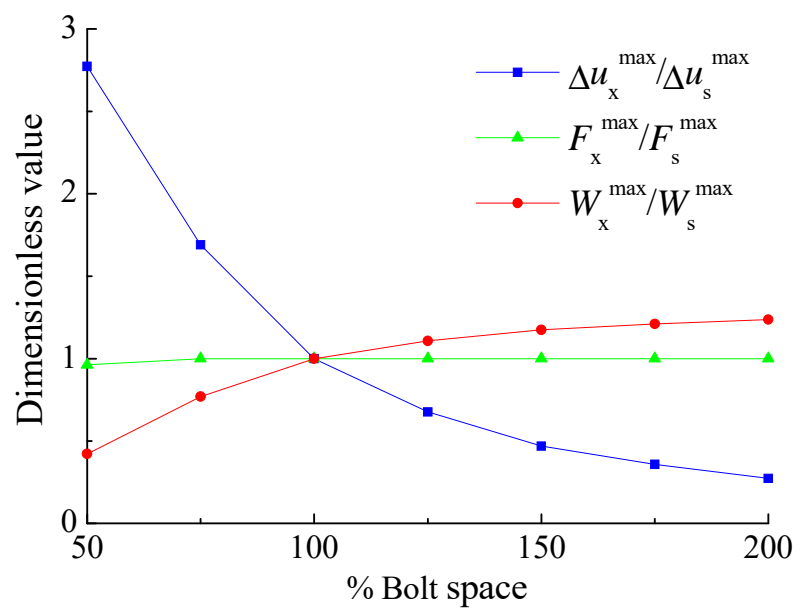

Fig. 13. The evolution of the tunnel convergence difference, the bolt axial force, and the bolt work as the bolt space increases.

The results show that decreasing the longitudinal spacing and the circumferential spacing (i.e., increasing the bolt installation density) may always be helpful in the stabilization of the surrounding rock mass. However, a high bolt density would be unnecessary and the bolt would not be fully utilized because the bolt work would be relative small, even when the maximum axial forces under different conditions are almost unchanged.

\subsection{Influence of the bolt length}

In the present study, the total bolt length was varied from $50 \%$ to $200 \%$ of its initial value $(3 \mathrm{~m})$. The length of the outer anchoring segment $(0.5 \mathrm{~m})$ and the inner anchoring segment $(0.7 \mathrm{~m})$ remained unchanged, and the length of the free-elongating segment was changed accordingly. Fig. 14 presents the evolution of the tunnel convergence difference, the bolt axial force, and the bolt work as the bolt length increases.

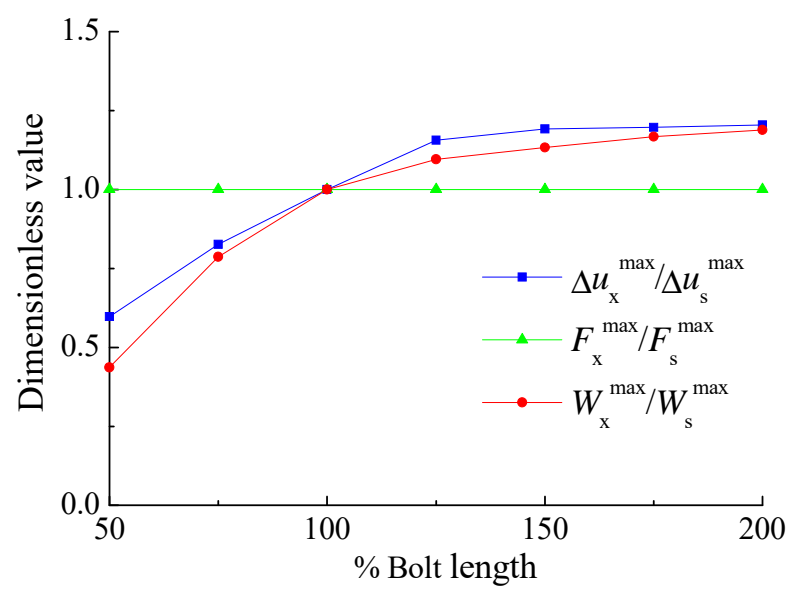

Fig. 14. The evolution of the tunnel convergence difference, the bolt axial force, and the bolt work as the 
bolt length increases.

When the bolt length is less than $4.5 \mathrm{~m}$, the tunnel convergence decreases significantly, as the bolt length increases. On the other hand, when the bolt length is longer than $4.5 \mathrm{~m}$, the supporting effect cannot be improved, even when the bolt is very long. This is because the radius of the plastic area is $4.23 \mathrm{~m}$ for the unsupported conditions, as shown in Fig. 7(a). Additional rock-bolt length would hardly affect the ground reinforcement, because the bolt section embedded in the elastic region of the rock mass would barely help to constrain the elastic displacement release (under the scope of continuous deformation media). Therefore, it is unnecessary to excessively extend the bolt beyond the range of the plastic region. The rock bolts of different bolt lengths have similar maximum axial forces; however, they present different reinforcement effects. The correlation of the bolt work and the reinforcement effect once again illustrates that the bolt work is a more effective estimation index.

\subsection{The influence of reinforcing time}

According to the convergence-confinement method, the influence of the reinforcing time could be studied by changing the mounted stage (artificial inner pressure $P_{i}$ ) of the rock bolt. In this study, the bolt-installation stage was varied from $25 \%$ (installed later) to $200 \%$ (installed earlier) of its initial value $\left(P_{0} * 37.5 \%\right)$. The evolution of the tunnel convergence difference, the bolt axial force, and the bolt work are shown in Fig. 15.

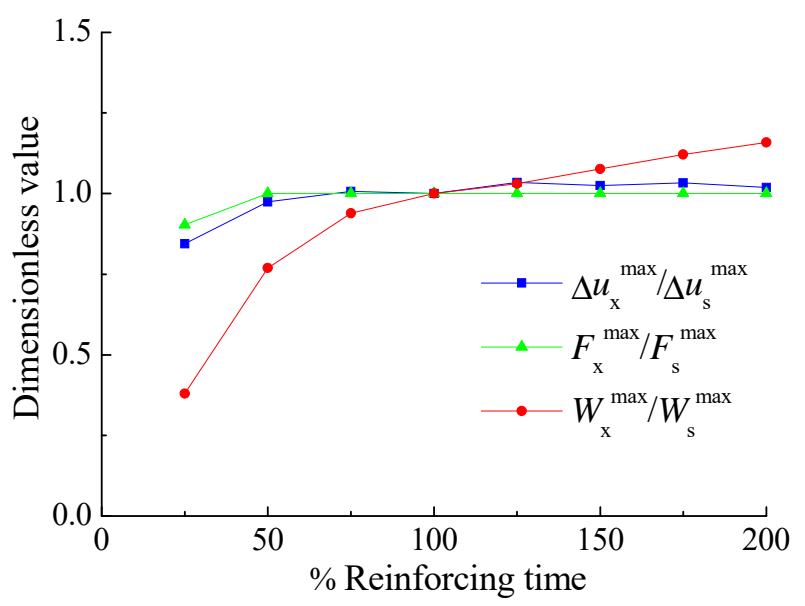

Fig. 15. The evolution of the tunnel convergence difference, the bolt axial force, and the bolt work as the bolt reinforcing time increases.

The rock bolt is mounted at the stage when $P_{i}^{(j)}=P_{0} * 37.5 \%$ in the illustrative case, and it equals to the critical inner pressure of the rock mass. When the reinforcing time is earlier than that of the illustrative case, no significant contribution can be observed in the tunnel convergence difference, and the increase in bolt work is fairly minor. If the energy-absorbing rock bolt is installed later than when it was installed in the 
illustrative case, the tunnel convergence difference and the bolt work would both significantly decrease, thus illustrating that the capacity of the energy-absorbing rock bolt is not fully utilized. It is recommended that the bolt should be installed no later than the stage of critical inner pressure, namely when the plastic region occurs.

\section{Conclusions}

The mechanical and deformation mechanism of the energy-absorbing rock bolts were reviewed. Then, a coupling model was proposed to describe the interaction between the energy-absorbing rock bolt and the rock mass. Based on the plane-strain axial symmetry assumption and the incremental theory of plasticity, equilibrium equations and compatibility equations of the matrix mass, as well as the response of the energy-absorbing rock bolt were theoretically deduced.

The proposed method was programmed in the VB development environment, and a semi-analytical solution for the coupling model was achieved. The reinforcement mechanism of the energy-absorbing rock bolt in conventional tunneling was clearly demonstrated through an illustrative case study. In addition, the validity of the proposed method was verified through numerical simulations.

Based on the proposed model, the influence of the stress conditions, the strength of the rock mass, the bolt density, the bolt length, and the reinforcing time were quantitatively estimated, and the evolution of the maximum axial force and the bolt work transferred on the rock mass were presented. The results revealed that the performance of the energy-absorbing rock bolt is significantly improved in high-stress and low-strength rock conditions. The bolt could significantly reduce the deformation of the plastic zone, whereas the control effect of the elastic zone is not particularly obvious. Therefore, it is unnecessary to excessively extend the bolt beyond the range of the plastic region. On the contrary, increasing the bolt installation density could always help to reinforce and stabilize the surrounding rock mass. The tunnel convergence is significantly influenced by the reinforcing time; earlier installation is preferred for the energy-absorbing rock bolt. The bolt work transferred on the rock mass is a more effective estimation index than the bolt maximum axial force.

This study was focused on the quasi-static mechanical work transfer ability of the energy-absorbing rock bolt. In the future, it is imperative that the reinforcement effect of the energy-absorbing rock bolt under impact conditions be studied, according to its mechanical work transfer ability in practical engineering.

\section{Acknowledgments}


This study is funded by the National Natural Science Foundation of China (No. 51279097, No. 51479108, No. 51379117, No. 51678155).

\section{References}

[1] Cantieni L, Anagnostou G. The interaction between yielding supports and squeezing ground. Tunn. Undergr. Space Technol. 2009; 24: 309-322.

[2] Zhang C, Feng X, et al. A top pilot tunnel preconditioning method for the prevention of extremely intense rockbursts in deep tunnels excavated by TBMs. Rock Mech. Rock Eng. 2012; 45: 289-309.

[3] Zhao X, Wang J, Cai M, et al. Influence of unloading rate on the strainburst characteristics of Beishan granite under true-triaxial unloading conditions. Rock Mech. Rock Eng. 2014; 47: 467-483.

[4] Chen B, Feng X, Li Q, et al. Rock burst intensity classification based on the radiated energy with damage intensity at Jinping II hydropower station, China. Rock Mech. Rock Eng. 2015; 48: 289-303.

[5] Li C. A practical problem with threaded rebar bolts in reinforcing largely deformed rock masses. Rock Mech. Rock Eng. 2007; 40 (5): 519-524.

[6] He M, Zhao F, Cai M, Du S. A novel experimental technique to simulate pillar burst in laboratory. Rock Mech. Rock Eng. 2015; 48(5): 1833-1848.

[7] Stillborg B. Professional users handbook for rock bolting. Zurich, Switzerland: Trans Tech Pub; 1994.

[8] Hoek E. et al. Support of underground excavation in hard rock. Rotterdam: Balkema; 1995.

[9] Neugebauer E. A new way to tackle safety in underground operations. Min. Const. 2008; 3(08): 24-25.

[10] Windsor C, Thompson A. A new friction stabilizer assembly for rock and soil reinforcement applications. Rock Sup. Min. Undergr. Const. 1992: 523-529.

[11] Li C, Stillborg B. Analytical models for rock bolts. Int. J. Rock Mech. Min. Sci. 1999; 36(8): 1013-1029.

[12] Cai Y, Esaki T, Jiang Y. A rock bolt and rock mass interaction model. Int. J. Rock Mech. Min. Sci. 2004; 41(7): 1055-1067.

[13] Cai Y, Jiang Y, Djamaluddin I, Iura T, Esaki T. An analytical model considering interaction behavior of grouted rock bolts for convergence-confinement method in tunneling design. Int. J. Rock Mech. Min. Sci. 2015; 76: 112-126.

[14] Guan Z, Jiang Y, Tanabasi Y. Reinforcement mechanics of passive bolts in conventional tunnelling. Int. J. Rock Mech. Min. Sci. 2007; 44(4): 625-636.

[15] Carranza-T C. Analytical and numerical study of the mechanics of rockbolt reinforcement around 
tunnels in rock masses. Rock Mech. Rock Eng. 2009; 42(2): 175-228.

[16] Tan C. Difference solution of passive bolts reinforcement around a circular opening in elastoplastic rock mass. Int. J. Rock Mech. Min. Sci. 2016; 81: 28-38.

[17] Farmer I W. Stress distribution along a resin grouted rock anchor. Int. J. Rock Mech. Min. Sci. Geomech. Abstr. 1975; 12: 347-351.

[18] Li C. A new energy-absorbing bolt for rock support in high stress rock masses. Int. J. Rock Mech. Mining Sci. 2010; 47: 396-404.

[19] Bobet A, Einstein H. Tunnel reinforcement with rockbolts. Tunn. Undergr. Space Technol. 2011; 26(1): $100-123$.

[20] Jager A. Two new support units for the control of rockburst damage. Rock Sup. Min. Undergr. Const. 1992: 621-631.

[21] Wang G, Wu X, Jiang Y, et al. Quasi-static laboratory testing of a new rock bolt for energy-absorbing applications. Tunn. Undergr. Space Technol. 2013; 38: 122-128.

[22] He M, Gong W, Wang J, et al. Development of a novel energy-absorbing bolt with extraordinarily large elongation and constant resistance. Int. J. Rock Mech. Min. Sci. 2014; 67: 29-42.

[23] Ansell A. Laboratory testing of a new type of energy absorbing rock bolt. Tunn. Undergr. Space Technol. 2005; 20: 291-300.

[24] Wang G, Wu X, Jiang Y, Huang N. Coupling model and calculation method of yielding bolt and rockmass. Rock and Soil Mechanics, 2014; 35(3): 887-895.

[25] Wu X, Jiang Y, Wang G, Li B. Analysis on the reinforcement effect of yielding rock bolt. Chinese Journal of Geotechnical Engineering, 2016, 38(2): 245-252. (in Chinese)

[26] Jiang Y, Wu X, Wang G, Li B, and Iura T. Interaction mechanism of yielding rock bolt and matrix mass. In: ISRM Congress 2015 Proceedings - Int'l Symposium on Rock Mechanics. Montreal; 10-13 May 2015. p. 1-9.

[27] Kilic A, Ysar E, Atis C. Effect of bar shape on the pullout capability of fully-grouted rock bolts. Tunn. Undergr. Space Technol. 2003; 18(1): 1-6.

[28] Cao C, Ren T, Cook C, Cao Y. Analytical approach in optimising selection of rebar bolts in preventing rock bolting failure. Int. J. Rock Mech. Min. Sci. 2014; 72: 16-25.

[29] Guan Z, JiangY, Tanabasi Y. Ground reaction analyses in conventional tunneling excavation. Tunn. Undergr. Space Technol. 2007; 22 (2): 230-237. 
[30] Carranza-T C, Fairhurst C. The elasto-plastic response of underground excavations in rock masses that satisfy the Hoek-Brown failure criterion. Int. J. Rock Mech. Min. Sci. 1999; 36 (6): 777-809.

[31] Carranza-T C, Fairhurst C. Application of convergence-confinement method of tunnel design to rock masses that satisfy the Hoek-Brown failure criterion. Tunnelling and Underground Space Technology $2000 ; 15$ (2): 187-213.

[32] Alonso E, Alejano L, Varas F, Fdez-Manin G, Carranza-Torres C. Ground reaction curves for rock masses exhibiting strain-softening behaviour. Int. J. Num. Anal. Meth. Geomech. 2003; 27(13): $1153-1185$.

[33] Oreste P. Analysis of structural interaction in tunnels using the convergence-confinement approach. Tunn. Undergr. Space Technol. 2003; 18 (4): 347-363. 